\title{
CHARACTERIZATION OF SELF-ASSEMBLED NANOFIBERS
}

\author{
M. E. Salmon ${ }^{*}$, P.E. Russell ${ }^{*}$ and E.B. Troughton Jr.* \\ * - AIF - North Carolina State University, Campus Box 7531, Raleigh, NC 27695, USA \\ ** - Thomas Lord Research Center, Lord Corporation, Box 8012, Cary, NC 27512, USA
}

Self-assembled structures are of increasing interest today due to the rapid progression of micro- and nano- scale engineering applications. In recent years much attention has been placed on understanding the formation and properties of monomolecular thin films, also known as selfassembled monolayers (SAMS), for use as corrosion inhibitors, lubricants, and adhesion promoters $^{1,2}$. Much of the advancement in this field has come from the unprecedented resolution of scanned probe microscopy, the scanning tunneling microscope (STM) and the atomic force microscope (AFM), invented in the mid to late 1980's.

Instead of coherent films, novel self-assembled nanofibers form over time on evaporated Al thin films when immersed in a solution of $0.1 \mathrm{wt} \%$ methylphosphonic acid (MPA) and absolute ethanol at room temperature ${ }^{3}$. The fibers are also observed on surfaces other than the intial Al within the solution. If the $\mathrm{Al}$ is deposited only on a small portion of the substrate, over time, fibers are found on both the initial $\mathrm{Al}$ as well as on areas adjacent to the remaining $\mathrm{Al}$ film. There appears to be a substrate dependence on the growth of the fibers. Figure 1. shows an AFM height image of the resulting fiber growth across a transition between a silicon nitride thin film and the underlying $\mathrm{Si}$ substrate after two weeks of growth. A significant decrease in the fiber density is observed along this transition. This transition can has been employed to create segregated, well supported fibers needed for further characterization of individual fibers.

AFM has proven to be a valuable tool to look at changes in morphology of the fibers with temperature. The nanofibers exhibit a remarkably high temperature resistance as compared to the $100^{\circ} \mathrm{C}$ melting temperature of pure MPA. Figure 2 shows the progression of a fiber covered $\mathrm{Al}$ surface subjected to an ex-situ heat treatment. The sample is placed in a pre-heated ceramic boat and placed within a tube furnace with a thermocouple gauge for 30 minutes in air. The sample is then removed and quenched back to room temperature and imaged. The first transformation of the fiber morphology is observed between $430^{\circ} \mathrm{C}$ and $460^{\circ} \mathrm{C}$ where it seems that the fibers are melting.

In conclusion, novel fibrous structures are formed on the surface of Aluminum and adjacent areas by immersion into a $.01 \mathrm{wt} \% \mathrm{MPA} /$ Ethanol solution over time. Currently, new techniques involving TEM, SEM, EDS and AFM are being developed to help determine the structure and properties of the individual fibers as well as the whole fabric. Additional results involving STEM, SEM, and EDS will be presented.

[1] - P.E. Laibinis, et al., Science 245 (1989) 845.

[2] - A. Ulman, An Introduction to Ultrathin Films, Academic Press, San Diego, USA (1991).

[3] - Salmon ME, et al., Proceedings of Microscopy and Microanalysis (2002) 845. 


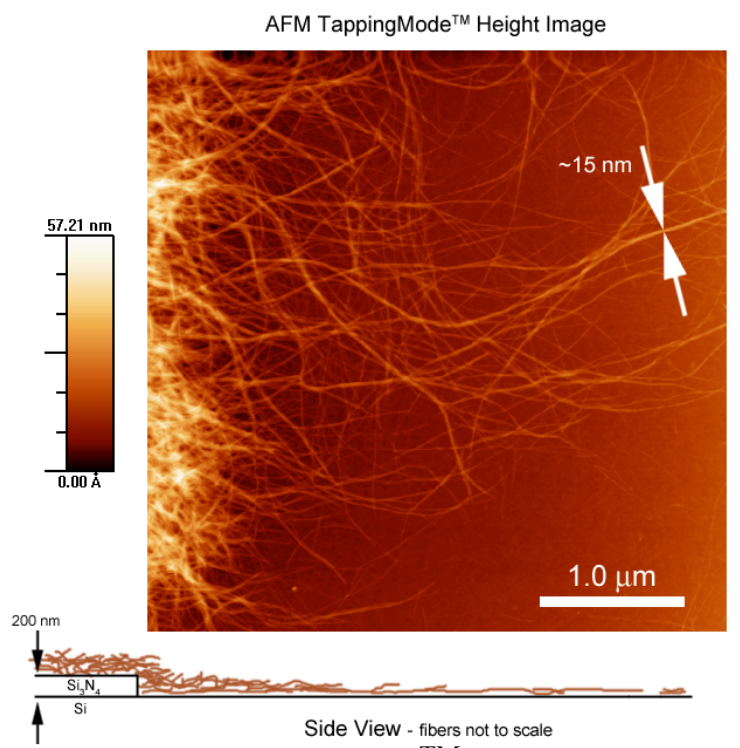

Figure 1. is a $4 \mu \mathrm{m} \times 4 \mu \mathrm{m}$ AFM TappingMode ${ }^{\mathrm{TM}}$ height image showing a transition in nanofiber growth across a transition. The density of fibers decreases dramatically as you transition from the $\mathrm{Si}_{3} \mathrm{~N}_{4}$ film to the underlying $\mathrm{Si}$ substrate.
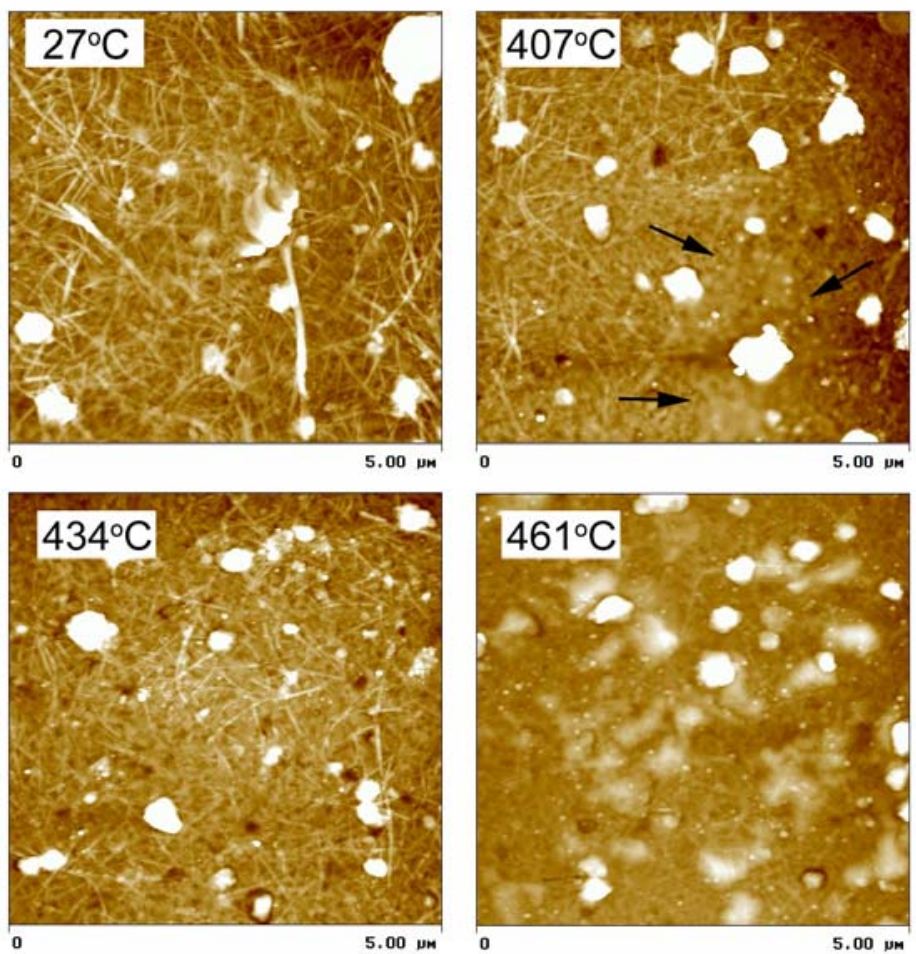

Figure 2. $5 \mu \mathrm{m} \times 5 \mu \mathrm{m}$ TappingMode ${ }^{\mathrm{TM}}$ AFM height images of different areas of the same sample showing the fiber morphology after progressive 30 minute ex-situ heat treatments in air. The first sign of changes occurring can be seen in the $407^{\circ} \mathrm{C}$ image where the arrows denotes the possible melting of a precipitate. The fibers stay intact until somewhere between $434^{\circ}$ and $461^{\circ} \mathrm{C}$ where we then see what appears to be melting of the structures. 